\title{
Effect of Chemical Activation on the Adsorption of Heavy Metals Using Activated Carbons from Waste Materials
}

\author{
F. T. Ademiluyi and E. O. David-West \\ Department of Chemical/Petrochemical Engineering, Rivers State University of Science and Technology, Port Harcourt, Nigeria \\ Correspondence should be addressed to F. T. Ademiluyi, ademuluyi@yahoo.com
}

Received 3 October 2012; Accepted 31 October 2012

Academic Editors: C. Chen and C. Xu

Copyright ( $) 2012$ F. T. Ademiluyi and E. O. David-West. This is an open access article distributed under the Creative Commons Attribution License, which permits unrestricted use, distribution, and reproduction in any medium, provided the original work is properly cited.

\begin{abstract}
The effect of chemical activation on the adsorption of metals ions $\left(\mathrm{Cr}^{2+}, \mathrm{Cu}^{2+}, \mathrm{Ni}^{2+}, \mathrm{Pb}^{2+}, \mathrm{Fe}^{2+}\right.$, and $\left.\mathrm{Zn}^{2+}\right)$ using waste Nigerian based bamboo, coconut shell, and palm kernel shell was investigated. The bamboo, coconut, and palm kernel shell were carbonized at $400^{\circ} \mathrm{C}-500^{\circ} \mathrm{C}$ and activated at $800^{\circ} \mathrm{C}$ using six activating agents. Chemical activation had significant effect on the iodine number and invariably increased the micropores and macropores of the activated carbons produced from bamboo, coconut, and palm kernel shell. It also affected the adsorption of metal ions and the type of carboneous material used for activation. The highest metal ions adsorbed were obtained from bamboo activated with $\mathrm{HNO}_{3}$. The cellulose nitrite formed during the activation of bamboo with $\mathrm{HNO}_{3}$ combined with high pore volume and low ash content of bamboo effectively create more reaction sites for adsorption of different metal ions. This shows that waste bamboo activated with $\mathrm{HNO}_{3}$ can effectively be used to remove metal ions from waste streams and in different metal recovery processes than activated carbon from coconut shell and palm kernel shell.
\end{abstract}

\section{Introduction}

The increased concern by environmentalist and government on the effect of heavy metals and $n$ attempt to protect public health gave rise to a lot of research in the development of advance technology to remove heavy metals from water and waste waters. The treatment efforts involved the application of unit processes such as chemical precipitation, coagulation, adsorption, ion exchange, and membrane filtration. Several works on activation of carboneous materials showed that the specific surface area, pore structure, and surface chemical functional groups of porous carbon determined their applications. The pore structure of porous carbon could be controlled by various routes, such as, activation conditions (activation agent, temperature, and time), precursor, templates, and so forth. The surface chemical functional groups are mainly derived from activation process, precursor, heat treatment, and postchemical treatment [1].

Yan and Viraraghavan [2] used different chemicals to study the effect of pretreatment of Mucor rouxii biomass on bioadsorption of $\mathrm{Pb}^{2+}, \mathrm{Cd}^{2+}, \mathrm{Ni}^{2+}$, and $\mathrm{Zn}^{2+}$. Pretreatment with detergent and alkali chemicals such as $\mathrm{NaOH}, \mathrm{Na}_{2} \mathrm{CO}_{3}$, and $\mathrm{NaHCO}_{3}$ were found to improve or maintain the bioadsorption capacity in comparison with live $\mathrm{M}$. rouxii biomass. Acid pretreatment using $\mathrm{HCl}, \mathrm{H}_{2} \mathrm{SO}_{4}$, and $\mathrm{C}_{2} \mathrm{H}_{4} \mathrm{O}_{2}$ resulted in a significant reduction in the bioadsorption capacity while alkali pretreatment was found to be more effective. Ramírez Zamora et al. [3] studied the adsorption capacities of mercury and silver by activating petroleum coke with $\mathrm{ZnCl}_{2}, \mathrm{NaOH}$, and $\mathrm{H}_{3} \mathrm{PO}_{4}$. The physicochemical characteristics determined for these activated carbons as well as scanning electron microscopy showed that the $\mathrm{H}_{3} \mathrm{PO}_{4}$ was the best activating agent. Effect of chemical activation using $\mathrm{KOH}$ and $\mathrm{K}_{2} \mathrm{CO}_{3}$ on activated carbon from Lignin from the work of Xiao et al. [4] showed that the activated carbon from Lignin activated using $\mathrm{K}_{2} \mathrm{CO}_{3}$ gave higher iodine number, surface area, and higher methylene blue number than those activated using $\mathrm{KOH}$.

The results obtained from previous studies reviewed above showed that different carboneous materials have different reactivity to different activating agents. Bamboo, palm kernel, and coconut shell have been found to be good materials for production of activated carbon $[5,6]$. The effectiveness of bamboo activated carbon to adsorbed heavy metal 
as not been compared with activated carbon from waste palm kernel and coconut shell. There is necessary to raise the activities of these carbons via chemical activation and compare the effectiveness of these three in adsorption of heavy metal ions from waste water streams. Therefore the objective of this study is to determine the effect of different chemical activations on the adsorption of heavy metals ions using activated carbons from waste materials such as bamboo, palm kernel shell, and coconut shell.

\section{Materials and Method}

2.1. Materials. The following materials and apparatus were used for this work: waste Nigeria based bamboo, and waste coconut shell, waste palm kernel shell. Activating agents are hydrochloric acid, phosphoric acid, sulphuric acid, nitric acid, zinc-chloride, and sodium hydroxide. A pyrolytic reactor was used for carbonization with condenser. Other materials used are measuring cylinder, heating mantle, desiccators, crucibles, funnels, and filter papers. Two electronic weighing balance, Ohaus top loading balance $(+0.01)$ was used to weigh the bamboo before pyrolysis, while a more sensitive electronic analytical weighing balance $(+0.001$, Adams AFP 360L) was used for another analysis, retort stand, thermocouple with temperature sensor, spatula, density bottle, crusher, sieves, measuring cylinders, moisture cans, and petri dish.

2.2. Carbonization. Known weight of waste coconut shell and waste palm kernel shell was cut into small sizes, washed, and dried. They were carbonized differently in a pyrolytic reactor at about $400-500^{\circ} \mathrm{C}$ for about two hours after which the charred products were allowed to cool to room temperature. The charred material was crushed using mortar and pistol and sieved.

2.3. Chemical Activation. The carbonised waste bamboo, palm kernel, and coconut shell were weighed separately and poured in different beakers containing known quantity of dilute hydrochloric acid, phosphoric acid, trioxonitrate (v) acid, tetraoxosulphate (vi) acid, zinc-chloride, and sodium hydroxide $\left(\mathrm{H}_{2} \mathrm{SO}_{4}, \mathrm{HCL}, \mathrm{ZnCl}_{2}, \mathrm{H}_{3} \mathrm{PO}_{4}, \mathrm{NaOH}\right.$, and $\mathrm{HNO}_{3}$ ). The concentrations of the acid used were already determined before this study. The content of the beakers was thoroughly mixed until a paste of each was formed. The pastes of the samples were then transferred to crucibles and the crucibles were placed in a Muffle furnace and were heated at $800^{\circ} \mathrm{C}$ for two hours. The activated samples were then cooled at room temperature, washed with distilled water to a $\mathrm{pH}$ of $6-7$, and dried in an oven at $105^{\circ} \mathrm{C}$ for three hours. The final products were sieved to same particle size kept in an air tight polyethylene bags, ready for use. Note that different concentrations (ranging from $0.025 \mathrm{M}-0.5 \mathrm{M}$ ) of each activating agents were prepared and used to activate waste bamboo, palm kernel, and coconut shells before the adsorption of the metal ions.

2.4. Characterization of Activated Carbons. The waste Nigerian based bamboo, waste coconut shell, and waste palm kernel shell used in this work were characterised (iodine number, Methylene blue number, density, etc.), using the ASTM methods as described in the work of Ademiluyi et al. [5].

2.5. Adsorption of Metal Ions in Aqueous Solution on Activated Carbons. Six metal ions $\left(\mathrm{Cr}^{2+}, \mathrm{Cu}^{2+}, \mathrm{Ni}^{2+}, \mathrm{Pb}^{2+}, \mathrm{Fe}^{2+}\right.$, and $\mathrm{Zn}^{2+}$ ) frequently found in industrial and municipal wastewater were chosen for this study. All metal ions in solutions were made by dissolving a known quantity of each salt containing these metals in distilled water in the ratio $1: 1000.2 \mathrm{~g}$ of the activated carbons activated with the six activating agents was added separately to the six mixtures containing each metal ion in solution and stirred for 30 minutes, it was filtered with a filter paper to get the filtrate. The same procedure was carried out for others $\left(\mathrm{Zn}^{2+}, \mathrm{Cr}^{3+}, \mathrm{Pb}^{2+}, \mathrm{Ni}^{2+}\right.$, and $\left.\mathrm{Fe}^{2+}\right)$.

The amount of metal ions in solution (i.e., $\mathrm{Zn}^{2+}, \mathrm{Cr}^{3+}$, $\mathrm{Pb}^{2+}, \mathrm{Ni}^{2}$, and $\mathrm{Fe}^{2+}$ ) was determined using conductometric method from the filtrate after adsorption using waste Nigerian based bamboo, waste coconut shell, and waste palm kernel shell. As described in the work of Banjonglaiad et al. [7], at low concentrations, conductivity is linearly related to the different metal ion concentrations so that if just one metal is present its concentration is readily established through calibration. Hence a calibration curve of concentration versus conductivity was first prepared for each metal ion. A commercial carbon was also used as control.

\section{Results and Discussion}

3.1. Effect of Chemical Activation on the Characterisation of Adsorbents. The iodine number is the most fundamental parameter used in characterizing activated carbon. It is a measure of activity level and the micropore content of the activated carbon (higher number indicates higher degree of activation, [8]). Figure 1 shows the variation of iodine number from different carbonaceous materials (waste bamboo, coconut, and palm kernel shell) and the various activating agents used for the activation. From the diagram, bamboo activated with $\mathrm{HNO}_{3}$ had the highest iodine number $1198 \mathrm{~g}$ of iodine $/ \mathrm{kg}$ of carbon, and the lowest iodine number was obtained carbon from palm kernel activated with $\mathrm{ZnCl}_{2}$ ( $419 \mathrm{~g}$ of iodine $/ \mathrm{kg}$ of carbon). Figure 1 shows that irrespective of the activating agents used, bamboo gives the highest iodine number than palm kernel and coconut shells. This means that activated carbon from waste bamboo has many chemically active sites than activated carbon produced from palm kernel and coconut shell. The highest iodine number obtained for coconut shell was obtained when $\mathrm{H}_{2} \mathrm{SO}_{4}$ was used as activating agents while highest iodine number for palm kernel was obtained when $\mathrm{HCl}$ was used as activating agent. This result indicates that activated carbon from bamboo is the best and also $\mathrm{HNO}_{3}$ is the best activating agent. This shows that there are reactions, that is, chemisorption taking place in the pores of the carbons during activation, and that the percentage composition of elements $(\mathrm{C}, \mathrm{H}, \mathrm{N}, \mathrm{S}$, etc.) in bamboo, coconut shell, and 


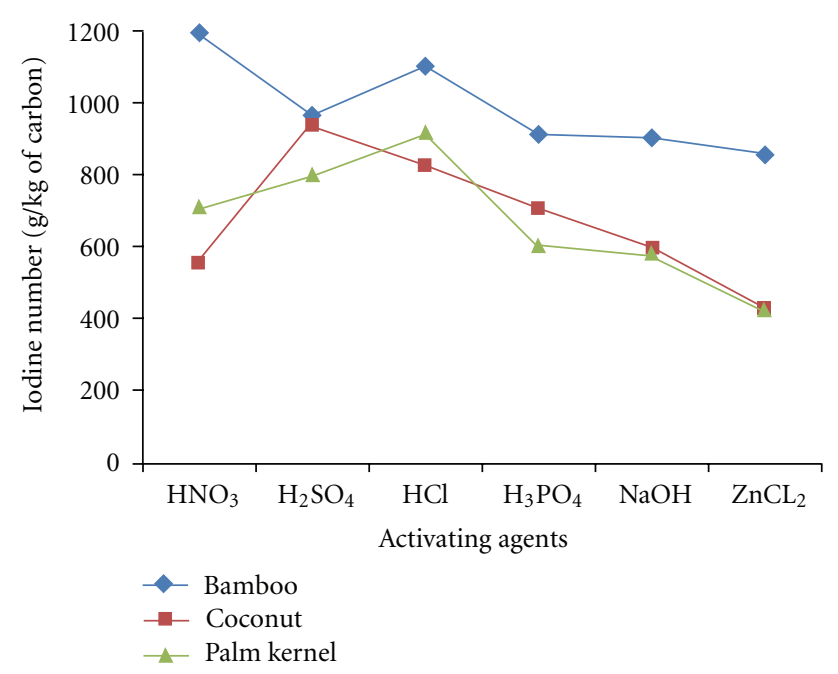

FIGURE 1: Effect of chemical activation on the iodine number of activated carbon from waste bamboo, coconut, and palm kernel shell.

palm kernel shell differs, which might have resulted in the differences in their reactivity with the different activating agents and the enlargement of their pore structure.

Similarly, in the work of Ramírez Zamora et al. [3], petroleum coke was activated with $\mathrm{ZnCl}_{2}, \mathrm{NaOH}$, and $\mathrm{H}_{3} \mathrm{PO}_{4}$. The degree of physicochemical alteration was significantly different for the three carbons obtained after activation with three chemicals. Activated carbon activated with $\mathrm{H}_{3} \mathrm{PO}_{4}$ being the strongest was able to adsorb mercury, and silver more effective than $\mathrm{NaOH}$ and $\mathrm{ZnCl}_{2}$.

3.2. Characterization of Activated Carbon from Bamboo, Coconut, Palm Kernel, and Other Reference Activated Carbons. Table 1 shows the properties of granular activated carbon from other reference activated carbons and that produced from bamboo, coconut, and palm kernel shell activated with $\mathrm{HNO}_{3}$. Palm kernel shell has the highest bulk density and bamboo the least. The low density of bamboo carbon will enhance quick adsorption in gas and liquid phase systems. The methylene blue adsorption capacity (which is a measure of meso- and macropores) for bamboo is higher than that of coconut and palm kernel shell after activation as shown in Table 1, which means that bamboo has higher mesopore structure than activated carbon from coconut shell and palm kernel shell. Also comparing the iodine number of activated carbon from bamboo, coconut, and palm kernel shell, it can be observed that the iodine number of bamboo activated carbon is higher than that produced from coconut and palm kernel shell. This means that the activated carbon from bamboo has larger micropore structure. Higher ash content in activated carbon from palm kernel than bamboo and coconut will reduce the overall activity of activated carbon from palm kernel [5]. Activated carbon from bamboo also had higher pore volume than activated carbon from coconut and palm kernel shell as shown in Table 1.

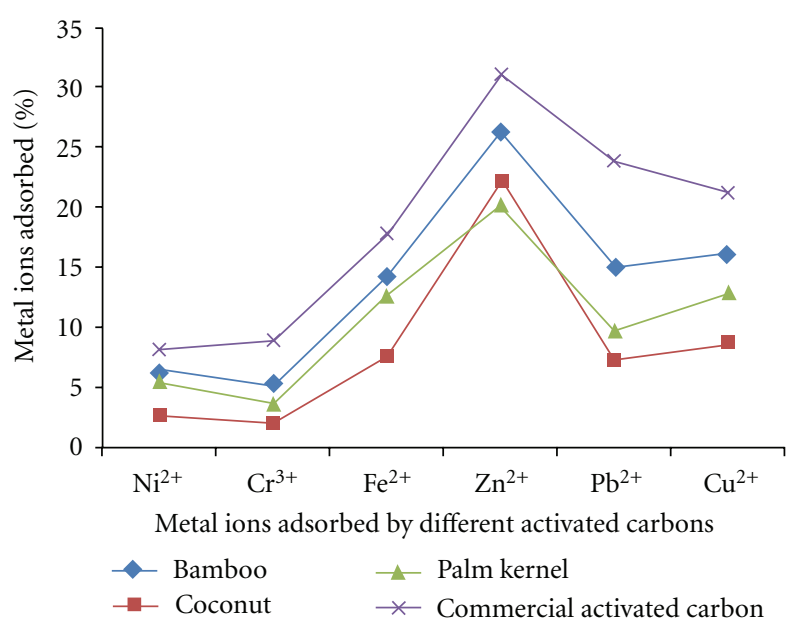

FIGURE 2: Adsorption of metal ions before activation of local adsorbents and commercial activated carbon.

3.3. Adsorption of Metal Ions before Activation of Adsorbents and Commercial Activated Carbon. Figure 2 shows the adsorption of metals ions $\mathrm{Cu}^{2+}, \mathrm{Ni}^{2+}, \mathrm{Cr}^{3+}, \mathrm{Zn}^{2+}, \mathrm{Pb}^{2+}, \mathrm{Fe}^{2+}$ using unactivated waste bamboo, unactivated waste coconut shell, unactivated waste palm kernel shell, and commercial activated carbon. It was observed that commercial activated carbon had the highest adsorption followed by activated carbon from bamboo, then palm kernel shell and lastly coconut within 30 mins of adsorption. This result was expected because the commercial activated carbon was activated whereas bamboo and palm kernel coconut carbons were not activated. This shows that activation of the three materials was necessary for effective adsorption of the metal ions. Unactivated carbon from bamboo still adsorbed all the metal ions more than coconut and palm kernel shell before activation.

The effect of activation on the adsorption of lead ion $\left(\mathrm{Pb}^{++}\right)$using activated carbon from waste bamboo, palm kernel and coconut shell is presented in Figure 3. The highest percentage of lead ion $\left(\mathrm{Pb}^{2+}\right)$ adsorbed was obtained from activated carbon from bamboo followed by activated carbon from waste coconut shell and then waste palm kernel shell irrespective of the activated agent used for activation carbons from bamboo, coconut, and palm kernel shells activated with $\mathrm{HNO}_{3}$ showed high adsorption for lead ions than other activating agents. It was observed that the amount of lead adsorbed by activated carbon, activated with nitric acid $\left(\mathrm{HNO}_{3}\right), \mathrm{H}_{2} \mathrm{SO}_{4}$, and $\mathrm{HCL}$ was significantly higher than carbons activated with $\mathrm{ZnCl}_{2}, \mathrm{NaOH}$, and $\mathrm{H}_{3} \mathrm{PO}_{4}$. This shows that adsorption of $\mathrm{Pb}^{2+}$ ions requires chemisorption than physical adsorption. Activation with $\mathrm{HNO}_{3}, \mathrm{H}_{2} \mathrm{SO}_{4}$, and HCL created more reactive sites for adsorption of lead ions. Also activated carbon produced from waste coconut shell adsorbed more lead ions than palm kernel shell after activation as shown in Figure 3 than before activation in Figure 2, which shows that acid activation increased the porosity of activated carbon from coconut shell after activation. 
TABLE 1: Characterization of activated carbon from bamboo, coconut, palm kernel, and other reference activated carbons.

\begin{tabular}{lcccccc}
\hline \multirow{2}{*}{ S/N } & \multirow{2}{*}{ Parameter } & \multirow{2}{*}{ Unit } & \multicolumn{3}{c}{ Locally made GAC } & \multirow{2}{*}{ References activated carbon } \\
\hline 1 & Bulk density & $\mathrm{g} / \mathrm{cm}^{3}$ & 0.458 & 0.8086 & 0.8332 & $0.2-0.6$ Long and Criscione [9] \\
& Methylene blue & $\mathrm{mg} / \mathrm{g}$ & 941.325 & 46.30755 & 42.230 & 900-1100 Wikipedia [8] \\
2 & adsorptive capacity & & & & & \\
3 & Iodine number & g of iodine/kg of C. & $1,197.45$ & 559.8971 & 709.20 & $500-1200$ Long and Criscione [9] \\
4 & Ash content & $\%$ & 2.760 & 0.98 & 6.435 & $\leq 8$ Metcalf and Eddy [10] \\
5 & Pore volume & $\mathrm{Cm}^{3}$ & 0.4543 & 0.1777 & 0.1731 & $0.5-2.5$ Long and Criscione [9] \\
\hline
\end{tabular}

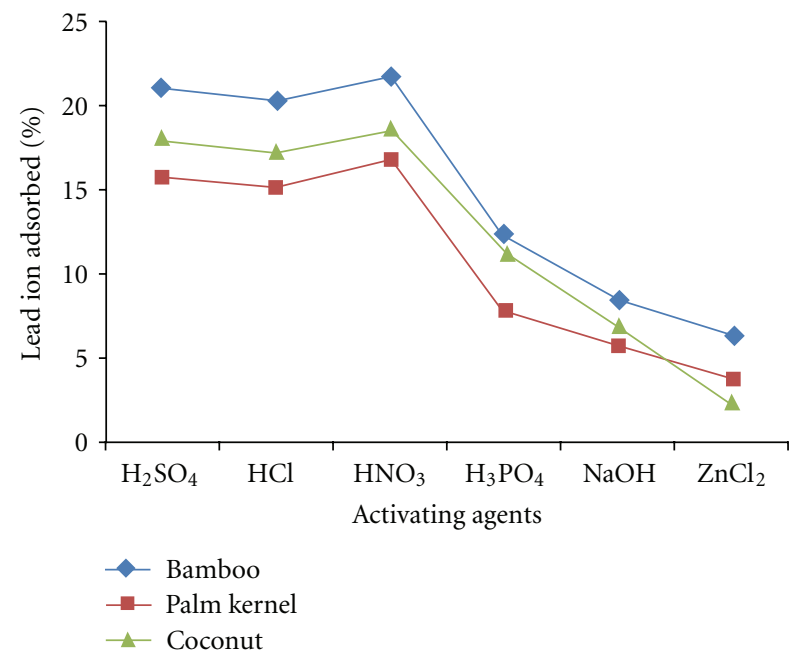

FIGURE 3: Effect of chemical activation on the adsorption of lead ion $\left(\mathrm{Pb}^{++}\right)$using waste bamboo, palm kernel shell, and coconut shell activated carbons.

The effect of chemical activation on the adsorption of iron II ions $\left(\mathrm{Fe}^{2+}\right)$ using activated waste bamboo, palm kernel, and coconut shells is presented in Figure 4. Activated carbon from bamboo still adsorbed the highest percentage of iron II ions, irrespective of the chemicals used for the activation than activated carbon from coconut shell and palm kernel shell. Bamboo carbon activated with $\mathrm{HNO}_{3}$ gave the highest percentage of iron II ions adsorbed. Also the amount of iron II ions adsorbed by carbons from bamboo, coconut, and palm kernel activated with $\mathrm{HNO}_{3}, \mathrm{H}_{2} \mathrm{SO}_{4}$, and $\mathrm{HCL}$ was significantly higher than carbons activated with $\mathrm{ZnCl}_{2}, \mathrm{NaOH}$ and $\mathrm{H}_{3} \mathrm{PO}_{4}$. This means that $\mathrm{HNO}_{3}, \mathrm{H}_{2} \mathrm{SO}_{4}$, and HCL increase the concentration of surface oxygen groups which reacts easily with lead and iron ions than $\mathrm{ZnCl}_{2}, \mathrm{NaOH}$, and $\mathrm{H}_{3} \mathrm{PO}_{4}$. Liu et al. [6] similarly reported that the adsorption of chromium VI ions was increased due to the presence of more acidic groups when nitric acid was used than when sodium hydroxide was used for activation.

A look at Figures 1-4 shows that bamboo activated carbon can effectively remove heavy metals ions than activated carbon from coconut shell and palm kernel shell. Hence the effect of chemical activation on the adsorption of other metal ions, that is, $\mathrm{Cr}^{3+}, \mathrm{Cu}^{2+}, \mathrm{Ni}^{2+}$, and $\mathrm{Zn}^{2+}$ was carried out using bamboo only. Figure 5 shows the effect of chemical

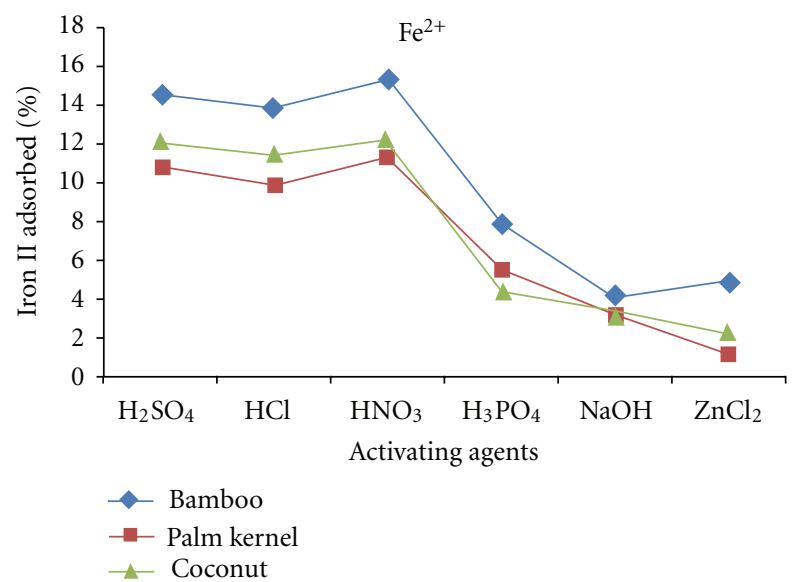

FIGURE 4: Effect of chemical activation on the adsorption of $\mathrm{Fe}^{2+}$ ions using activated waste bamboo palm kernel and coconut shells carbons.

activation on the adsorption of $\mathrm{Cr}^{3+}, \mathrm{Cu}^{2+}, \mathrm{Ni}^{2+}$, and $\mathrm{Zn}^{2+}$ ions in solution using activated carbon from bamboo. The adsorption of $\mathrm{Cu}^{2+}, \mathrm{Ni}^{2+}$, and $\mathrm{Zn}^{2+}$ followed the same trend with bamboo activated with $\mathrm{HNO}_{3}, \mathrm{H}_{2} \mathrm{SO}_{4}$, and $\mathrm{HCL}$ adsorbing more metals ions than bamboo activated with $\mathrm{ZnCl}_{2}, \mathrm{NaOH}$ and $\mathrm{H}_{3} \mathrm{PO}_{4}$ as shown in Figure 5. The effect of chemical activation on chromium ions $\mathrm{Cr}^{3+}$ adsorption followed a different trend, with a reduction in $\mathrm{Cr}^{3+}$ ions adsorbed using $\mathrm{H}_{2} \mathrm{SO}_{4}$. It has been reported [11] that sulphur in $\mathrm{H}_{2} \mathrm{SO}_{4}$ may cause a reduction in porosity of the carbon and that when bamboo reacts with $\mathrm{H}_{2} \mathrm{SO}_{4}$, it produces surplus water and sulphur which may reduce adsorption of $\mathrm{Cr}^{3+}$ ions.

Figure 6 shows the adsorption of different metal ions using bamboo activated with $\mathrm{HNO}_{3}$ and commercial activated carbon. Bamboo after activation adsorbed more metal ions than the commercial activated carbon, unlike the result obtained earlier in Figure 1. This shows that bamboo activated with $\mathrm{HNO}_{3}$ can effectively be used to remove metal ions from waste streams than activated carbon from coconut and palm kernel shell. $\mathrm{HNO}_{3}$ was reported by Ademiluyi et al. [12] to produce a highly reactive product known as cellulose nitrite during the adsorption of bamboo with benzene. The reaction of the cellulose in bamboo with $\mathrm{HNO}_{3}$ is shown in (1). Cellulose nitrite in turn reacts with benzene to produce an alkyl cellulose nitrate. $\mathrm{NO}_{2}{ }^{+}$thus forms a sigma complex 


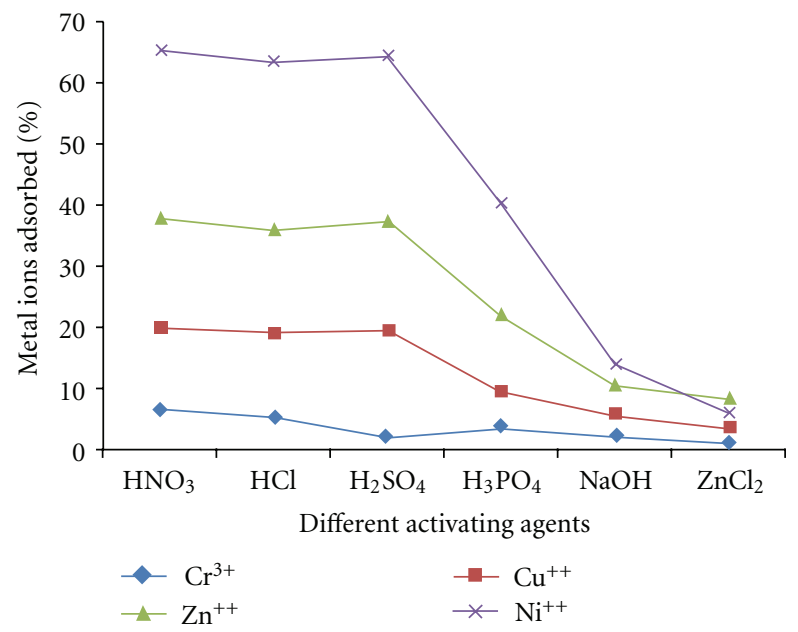

Figure 5: Effect of chemical activation on the adsorption of $\mathrm{Cr}^{3+}$, $\mathrm{Cu}^{2+}, \mathrm{Ni}^{2+}$, and $\mathrm{Zn}^{2+}$ ions in solution using activated carbon from bamboo.

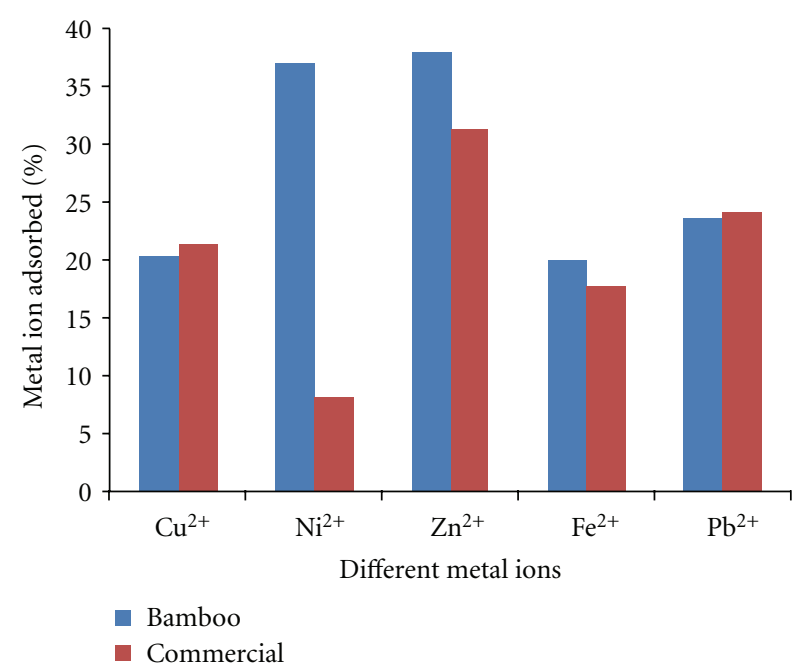

FIgURe 6: Adsorption of different metal ions using bamboo activated with $\mathrm{HNO}_{3}$ and commercial activated carbon.

with many chemicals, making $\mathrm{HNO}_{3}$ a reactive activating agent as follows:

$$
3 \mathrm{HNO}_{3}+\mathrm{C}_{6} \mathrm{H}_{10} \mathrm{O}_{5} \longrightarrow \mathrm{C}_{6} \mathrm{H}_{7}\left(\mathrm{NO}_{2}\right)_{3} \mathrm{O}_{5}+3 \mathrm{H}_{2} \mathrm{O} .
$$

\section{Conclusion}

The effect of chemical activation using different activating agents on the adsorption of heavy metals ions using activated carbons from waste materials such as bamboo, palm kernel shell, and coconut shell has been investigated. Chemical activation had a significant effect on the adsorption of metal ions and on the type of carboneous material used. The adsorption of metal ions using bamboo, coconut, and palm kernel activated with $\mathrm{HNO}_{3}, \mathrm{H}_{2} \mathrm{SO}_{4}$, and $\mathrm{HCL}$ was significantly higher than carbons activated with $\mathrm{ZnCl}_{2}, \mathrm{NaOH}$, and
$\mathrm{H}_{3} \mathrm{PO}_{4}$. The highest metal ion adsorbed was obtained from bamboo activated with $\mathrm{HNO}_{3}$. The cellulose nitrite formed during the activation of bamboo with $\mathrm{HNO}_{3}$ created more active reaction site for adsorption of different metal ions. This shows that waste bamboo activated with $\mathrm{HNO}_{3}$ can effectively be used to remove metal ions from waste streams and in different metal recovery processes than coconut and palm kernel.

\section{References}

[1] W. Shen, Z. Li, and Y. Liu, "Surface chemical functional groups modification of porous carbon," Recent Patents on Chemical Engineering, vol. 1, no. 1, pp. 27-40, 2008.

[2] G. Yan and T. Viraraghavan, "Effect of pretreatment on the bioadsorption of heavy metals on mucor rouxii," Water $S A$, vol. 26, no. 1, pp. 119-123, 2000.

[3] R. M. Ramírez Zamora, R. Schouwenaars, A. Durán Moreno, and G. Buitrón, "Production of activated carbon from petroleum coke and its application in water treatment for the removal of metals and phenol," Water Science and Technology, vol. 42, no. 5-6, pp. 119-126, 2000.

[4] J. J. Xiao, Y. Zhi-Ming, and Y. Wu, "Preparation of activated carbon from lignin obtained by straw pulping by $\mathrm{KOH}$ and $\mathrm{K}_{2} \mathrm{CO}_{3}$ Chemical activation," Cellulose Chemistry and Technology, vol. 46, no. 1-2, pp. 79-85, 2012.

[5] F. T. Ademiluyi, R. Gumus, S. M. Adeniji, and O. I. Jasem, "Effect of process conditions on the characterization of activated carbon from waste Nigerian bamboo," Journal of Nigerian Society of Chemical Engineers, vol. 24, no. 1-2, pp. 83-94, 2009.

[6] S. X. Liu, X. Chen, X. Y. Chen, Z. F. Liu, and H. L. Wang, "Activated carbon with excellent chromium(VI) adsorption performance prepared by acid-base surface modification," Journal of Hazardous Materials, vol. 141, no. 1, pp. 315-319, 2007.

[7] T. Banjonglaiad, E. Croiset, P. Silveston et al., "Dynamic measurement of copper (II) ion adsorption in activated carbon fixed bed columns," The American Journal of Environmental Sciences, vol. 4, no. 4, pp. 412-419, 2008.

[8] “Activated carbon," 2012, http://en.wikipedia.org/wiki/Activated_carbon.

[9] J. C. Long and J. M. Criscione, "Carbon survey," in KirkOthmer Encyclopedia of Chemical Technology, p. 733, John Wiley \& Sons, New York, NY, USA, 2003.

[10] Metcalf and Eddy, Wastewater Engineering, Treatment and ReUse, John Wiley \& Sons, New York, NY, USA, 6th edition, 2003.

[11] L. K. Edward, W. H. Mui Cheung, M. Valix, and G. Mckay, "Activated carbons from bamboo scaffolding using acid activation," Separation and Purification Technology, vol. 74, no. 2, pp. 213-218, 2010.

[12] F. T. Ademiluyi, A. C. Ogbonna, and O. Braide, "Effectiveness of Nigerian bamboo activated with different activating agents on the adsorption of BTX," in Proceedings of the 40th Annual Conference of Nigerian Society of Chemical Engineers, pp. 199209, 2010. 

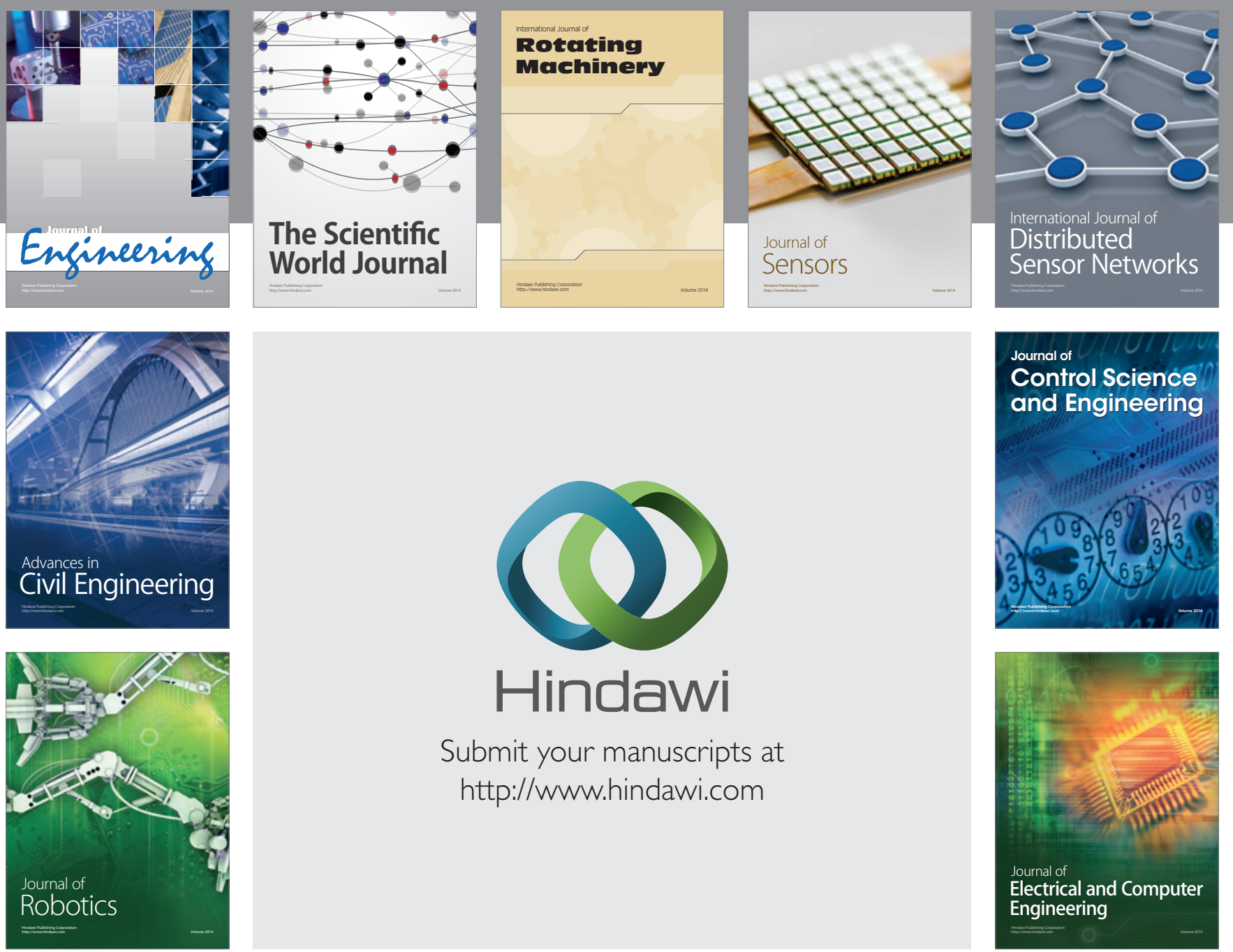

Submit your manuscripts at

http://www.hindawi.com
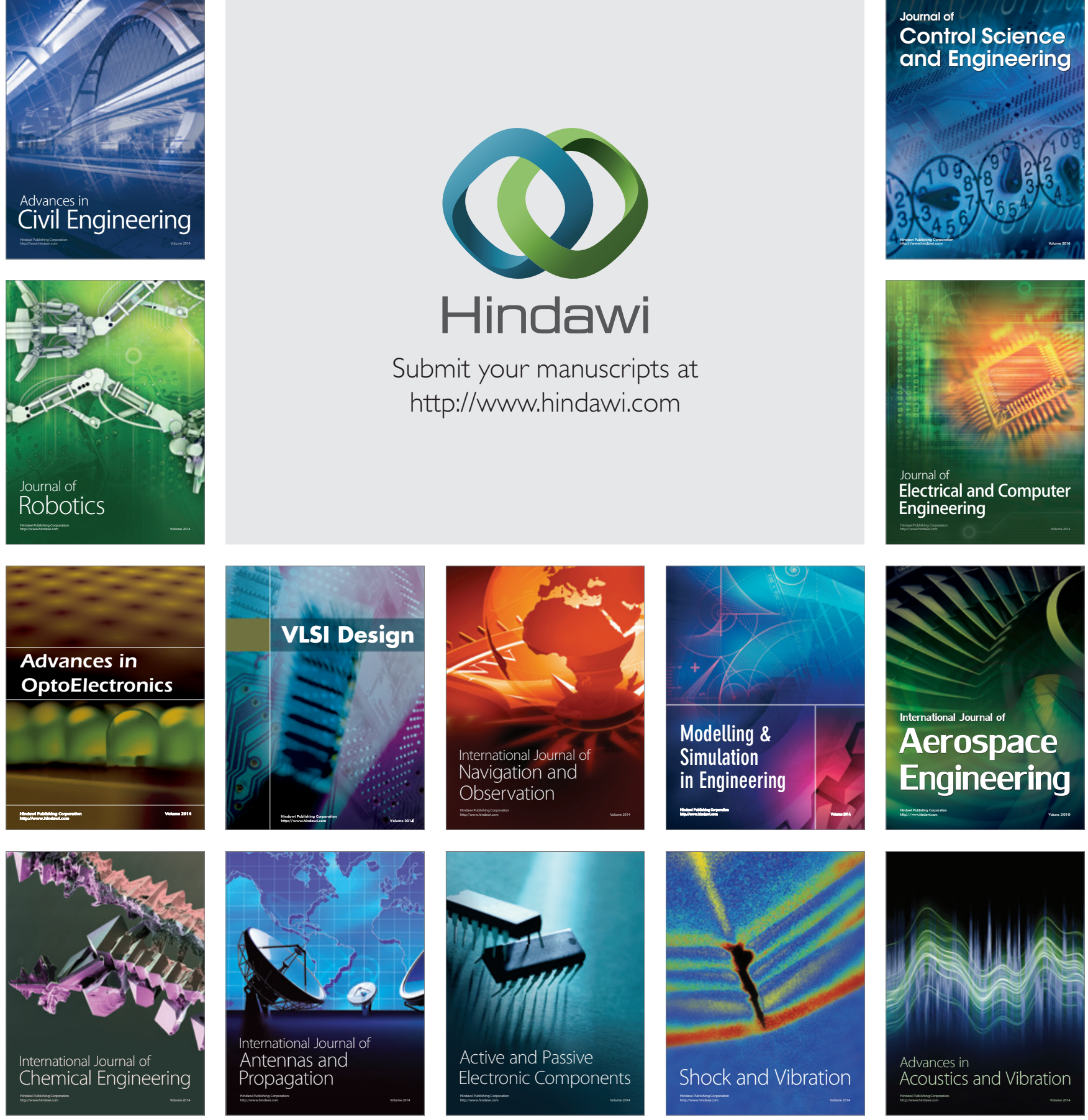